\title{
MENINGKATKAN KETERAMPILAN GURU PAUD DALAM MENANGANI ANAK BERKEBUTUHAN KHUSUS (ABK) DI PAUD
}

\author{
Ana Rafikayati1 ${ }^{1)}$, Lutfi Isni Badiah ${ }^{2)}$, Mudhar ${ }^{3)}$ \\ ${ }^{1,2}$ Program Studi Pendidikan Khusus, Universitas PGRI Adi Buana Surabaya \\ Email: ana@unipasby.ac.id , lutfi@unipasby.ac.id \\ ${ }^{3}$ Program Studi Bimbingan dan Konseling, Universitas PGRI Adi Buana Surabaya \\ Email: mudhar.bps@gmail.co.id
}

\begin{abstract}
Abstrak
Tujuan dari kegiatan pelatihan identifikasi dan asesmen anak berkebutuhan khusus adalah untuk meningkatkan: 1) pengetahuan guru PAUD mengenai jenis-jenis ABK, 2) meningkatkan keterampilan guru PAUD dalam melakukan identifikasi ABK, dan 3) meningkatkan keterampilan guru PAUD dalam mengasesmen ABK. Kegiatan ini diikuti oleh 20 orang guru PAUD dari sekolah PAUD Peek A Boo dan PAUD Permata Bunda Sidoarjo. Metode yang digunakan dalam kegiatan pelatihan adalah ceramah, diskusi kelompok, dan praktek. Hasil dari kegiatan ini diperoleh bahwa setelah mengikuti pelatihan adalah: 1) terjadi peningkatan pengetahuan guru PAUD mengenai jenis-jenis ABK yakni dari 65\% menjadi 90\%, 2) Keterampilan guru dalam mengidentifikasi juga mengalami peningkatan, dari 10\% menjadi 55\% mampu mengidentifikasi ABK, serta 3) adanya peningkatan dalam kegiatan asesmen ABK, dari 10\% menjadi 50\%. Dengan demikian, pelatihan ini efektif dapat meningkatkan pengetahuan dan keterampilan guru PAUD dalam kegiatan identifikasi dan asesmen anak berkebutuhan khusus (ABK).
\end{abstract}

Kata Kunci: Keterampilan Guru PAUD, Identifikasi, Asesmen

\begin{abstract}
The purpose of identifying and assessing children with special needs training is to improve: 1) early childhood teacher's knowledge about types of special needs children, 2) skills of early childhood teacher in identifying special needs children, and 3) skills of early childhood teacher in assessing special needs children. This activity was attended by 20 early childhood teacher from Peek A Boo School and Permata Bunda Schools in Sidoarjo. The methods used in training activities are lectures, group discussions, and practices. The results of this activity were obtained that after attending the training: 1) there was an increase in the knowledge of early childhood teacher regarding the types of children with special needs from $65 \%$ to 90\%, 2) The skills of teachers in identifying also increased, from $10 \%$ to $55 \%$ able to identify children with special needs, and 3) an increase in assessment activities of children with special needs, from $10 \%$ to $50 \%$. Thus, this training can effectively increase the knowledge and adequacy of early childhood teacher to identification and assessment activities of children with special needs.
\end{abstract}

Keywords: Early Childhood Teacher, Identification, Assessment

\section{PENDAHULUAN}

Sejak diperkenalkan mulai tahun 2004, penyelenggaraan sekolah inklusi di Indonesia telah menjadi fokus Pemerintah Indonesia. Hal ini sebagai bentuk perwujudan komitmen Pemerintah Indonesia dalam menyediakan pendidikan bagi semua warga negara termasuk anak berkebutuhan khusus (ABK) sebagaimana yang telah diamanatkan dalam
Undang-Undang Dasar (UUD) 1945. Namun dengan adanya penyelenggaraan pendidikan inklusif ini, sekaligus juga membawa konsekuensi besar bagi guru di sekolah reguler.

Guru di sekolah reguler dituntut untuk mempunyai pengetahuan tentang ABK, diantaranya harus mampu mengetahui siapa ABK, karakteristik, dan bagaimana 
penanganannya di sekolah. Untuk dapat mengenali dan menangani $\mathrm{ABK}$, maka perlu dilakukan identifikasi dan asesmen bagi peserta didik terlebih dahulu di sekolah. Identifikasi dan asesmen ABK harus dilakukan sedini mungkin. Semakin dini identifikasi dan asesmen, maka semakin baik. Tujuannya adalah agar ABK dapat segera dibuatkan program layanan yang sesuai dengan kebutuhannya masing-masing.

Penyelenggarakan pendidikan inklusif di Indonesia menyeluruh dalam semua jenjang termasuk jenjang PAUD. Pendidikan Anak Usia Dini (PAUD) merupakan suatu lembaga yang menjadi tahap pertama bagi anak memasuki dunia pendidikan. Dalam pasal 28 UU No 20 tahun 2003, ditegaskan bahwa penyelenggaraan pendidikan anak usia dini adalah sebagai berikut.

1. PAUD diselenggarakan sebelum pendidikan dasar;

2. PAUD dapat diselenggarakan melalui pendidikan formal, nonformal dan atau informal;

3. PAUD pada jalur pendidikan formal terbentuk TK, RA, aau bentuk lain yang sederajad;

4. PAUD pada jalur pendidikan nonformal terbentuk KB, TPA atau bentuk lain yang sederajad;

5. PAUD pada jalur informal tebentuk pendidikan keluarga atau pendidikan yang diselenggarakan oleh lingkungan.

Menurut (Yaum \& Mais, 2017), dampak dari penyelenggaraan pendidikan inklusif di PAUD juga membawa konsekuensi bagi guru PAUD dalam menyiapkan pembelajaran yang berbasis pada kebutuhan individual siswa usia dini di kelas. Tanggung jawab guru tidak hanya sebatas pada pengembangan aspek akademik, namun juga pengembangan aspek sosial, aspek emosional, aspek moral, dan aspek agama. Pada saat anak memasuki sekolah PAUD inilah mulai ditemukan indikasi-indikasi penyimpangan tumbuh kembang pada anak atau yang mengarah pada kebutuhan khusus. Sebenarnya indikasi tersebut bisa diketahui sebelum masuk usia PAUD. Namun karena ketika di rumah, orang tua kurang pengetahuan tentang penyimpangan tumbuh kembang atau bahkan anak kurang mendapatkan perhatian dari orang tua, maka indikasi tersebut kurang menjadi perhatian.

Hal inilah yang kemudian menjadi tugas guru PAUD untuk dapat membantu mengenali tanda-tanda penyimpangan tumbuh kembang anak sedini mungkin. Menurut Kismawiyati (2018), identifikasi ABK di lembaga PAUD yang dilakukan sejak dini merupakan awal yang baik untuk mencapai tujuan pendidikan di PAUD. Anak berkebutuhan khusus yang terjaring, perlu segera diberikan bantuan pendidikan khusus. Pelaksanaan identifikasi ini penting karena akan berdampak besar bagi keberlanjutan tumbuh kembang dan pendidikan anak khususnya $\mathrm{ABK}$.

Adnan, dkk (2012) mengemukakan bahwa para pendidik anak usia dini di lembaga PAUD masih mengalami banyak kesulitan dalam menemukenali atau mengidentifikasi memahami karakteristik ABK di kelasnya. Hal ini juga menjadi permasalahan tersendiri bagi kedua sekolah PAUD tersebut. Guru masih belum sepenuhnya paham tentang ABK dan karakteristiknya. Sebagaimana hasil survei yang telah dilakukan oleh (Suryaningrum, Ingarianti, \& Anwar, Januari 2016) terhadap 45 guru PAUD di Kota Malang bahwa terdapat 60\% guru PAUD tidak tahu karakteristik ABK, sebanyak 70\% guru PAUD yang tidak tahu cara untuk melakukan identifikasi $\mathrm{ABK}$, dan sebanyak $60 \%$ guru PAUD juga tidak tahu cara mengasesmen ABK.

Hal ini tentu saja menyebabkan ABK sulit untuk belajar di kelasnya. Pelatihan identifikasi dan asesmen ABK menjadi salah satu cara untuk membantu guru PAUD agar dapat menangani ABK. Tujuan dari kegiatan pengabdian kepada masyarakat ini adalah memberikan pelatihan identifikasi dan asesmen $\mathrm{ABK}$ untuk meningkatkan keterampilan guru PAUD dalam menangani anak berkebutuhan khusus (ABK). Sehingga diharapkan guru dari sekolah PAUD Peek A Boo dan PAUD Permata Bunda meningkatkan kemampuan dalam 
identifikasi dini $\mathrm{ABK}$ dan asesmen di sekolahnya.

\section{METODE PELAKSANAAN}

Subyek penelitian ini adalah seluruh guru di sekolah PAUD Peek A Boo dan PAUD Permata Bunda yang di Delta Raya Utara No.66, Waru, Kabupaten Sidoarjo dan Jl. Cendrawasih No.22C Kec. Betro Sedati, Kabupaten Sidoarjo yang seluruhnya berjumlah 20 orang.

Adapun metode dan rancangan kegiatan ini diuraikan sebagaimana berikut.

a. Perencanaan

Kegiatan ini dimulai dengan: (1) koordinasi dengan LP2M UNIPA Surabaya, PAUD Peek A Boo dan PAUD Permata Bunda, Merumuskan strategi dan setting pelatihan, dan (3) merancang instrumen pre-test dan post test, instrumen identifikasi ABK dan modul pelatihan identifikasi $A B K$ dan implementasi identifikasi $\mathrm{ABK}$ di sekolah guru.

b. Pelaksanaan Kegiatan

Pelaksanaan kegiatan ini terdiri:

1) Kegiatan pretest untuk menggali data awal mengenai keterampilan guru PAUD dalam mengidentifikasi ABK di sekolahnya. Dari kegiatan ini diketahui bahwa pengetahuan guru tentang karakteristik $\mathrm{ABK}$ sangat minim, dan sulit untuk melakukan identifikasi.

2) Pelatihan dengan guru sekolah mitra guna penyampaian materi identifikasi dan asesmen $\mathrm{ABK}$, guru juga diminta untuk melakukan identifikasi ABK di sekolahnya dan melaporkan hasil kegiatan identifikasi ABK di sekolah masing-masing;

3) Kegiatan Post test untuk mengetahui adanya peningkatan pelatihan identidikasi ABK terhadap keterampilan guru di sekolah PAUD Peek A Boo dan PAUD Permata Bunda atau tidak.

\section{HASIL DAN PEMBAHASAN Kegiatan Pretest}

Hasil dari pretest yang dilakukan sebelum pelatihan, didapat data bahwa guru baik dari sekolah PAUD Peek a Boo dan PAUD Permata Bunda belum pernah mendapatkan pelatihan mengenai identifikasi dan asesmen ABK. Mereka juga mengemukakan bahwa pengetahuan tentang ABK masih terbatas. Persepsi $\mathrm{ABK}$ adalah anak yang secara fisik seperti tidak punya anggota gerak, buta, tuli wicara, dan keterbelakangan mental. Sedangkan untuk karakteristik rinci masingmasing kebutuhan khusus, para guru tersebut mengaku belum mengetahui secara rinci. Sebanyak 65\% mengetahui jenis-jenis ABK, sebanyak $10 \%$ mampu mengidentifikasi ABK, dan $10 \%$ mampu mengasesmen ABK.

\section{Kegiatan Pelatihan}

Kegiatan pelatihan dilakukan pada 5 Mei dan 12 Mei 2018 di bertempat di PAUD Peek a Boo. Adapun pelaksanaan pada tanggal 5 Mei 2018 adalah penyampaian materi yang berlangsung dari pukul 07.30-15.30 WIB. Adapun materi dan agenda pelatihan adalah sebagai berikut.

\begin{tabular}{|c|c|c|c|}
\hline No & Waktu & Uraian Materi & Pemateri \\
\hline 1. & $\begin{array}{l}07.30- \\
07.45\end{array}$ & Registrasi & Panitia \\
\hline 2. & $\begin{array}{l}07.45- \\
08.00\end{array}$ & Pembukaan & Panitia \\
\hline 3. & $\begin{array}{l}08.00- \\
10.00\end{array}$ & $\begin{array}{l}\text { Sesi 1: } \\
\text { Karakteristik } \\
\text { Masing- } \\
\text { Masing ABK }\end{array}$ & $\begin{array}{l}\text { Lutfi Isni } \\
\text { Badiah, } \\
\text { S.Pd., } \\
\text { M.Pd }\end{array}$ \\
\hline 4. & $\begin{array}{l}10.00- \\
12.00\end{array}$ & $\begin{array}{l}\text { Sesi 2: } \\
\text { Identifikasi } \\
\text { ABK dan } \\
\text { Asesmen } \\
\text { ABK }\end{array}$ & $\begin{array}{l}\text { Ana } \\
\text { Rafikayati, } \\
\text { S.Pd., } \\
\text { M.Pd }\end{array}$ \\
\hline 5. & $\begin{array}{l}12.00- \\
13.00\end{array}$ & Istirahat & Panitia \\
\hline 6. & $\begin{array}{l}13.00- \\
15.00\end{array}$ & $\begin{array}{l}\text { Sesi } 3 \text { : } \\
\text { Penggunaan } \\
\text { Instrumen } \\
\text { Identifikasi } \\
\text { dan Asesmen } \\
\text { ABK }\end{array}$ & $\begin{array}{l}\text { Mudhar, } \\
\text { S.Psi., } \\
\text { M.Si }\end{array}$ \\
\hline
\end{tabular}




$\begin{array}{llll}\text { No } & \text { Waktu } & \text { Uraian Materi } & \text { Pemateri } \\ \text { 7. } & 15.00- & \text { Penutupan } & \text { Panitia } \\ & 15.30 & & \end{array}$

Antusias peserta pelatihan sangat terlihat jelas dari banyaknya pertanyaan seputar kegiatan pembelajaran sehari-hari. Sebagian guru bahkan baru mengetahui yang termasuk ABK bukan hanya anak yang tidak punya anggota gerak, buta, tuli wicara, dan keterbelakangan mental. Namun juga anak yang mengalami gangguan perilaku juga termasuk ABK. Perilaku agresif anak yang sering ditampilkan anak di kelas juga menjadi topik diskusi dalam pelatihan ini. Guru mengaku seringkali kewalahan dalam menghadapi anak yang berperilaku agresif, hiperaktif, dan gangguan konsentrasi.

Setelah mendapatkan materi mengenai karakteristik ABK, identifikasi dan asesmen ABK. Serta penggunaan instrumen identifikasi, guru kemudian diminta untuk melakukan identifikasi dan asesmen di kelasnya masing-masing. Hal ini untuk mengetahui sejauh mana peningkatan keterampilan guru terhadap ABK. Selama kegiatan identifikasi, guru didampingi oleh pemateri melalui online lecturing dan disediakan pula forum diskusi melalui google classroom. Hasil identifikasi yang telah dilaksanakan kemudian dilaporkan pada pertemuan post-test.

\section{Kegiatan Posttest}

Kegiatan ini dilakukan untuk mengukur peningkatan keterampilan guru PAUD dalam mengidentifikasi ABK. Setelah pelaksaanaan pelatihan, guru diminta untuk melakukan identifikasi di kelasnya. Dalam melakukan proses identifikasi, terdapat guru yang masih kesulitan, diberikan pendampingan secara online lecturing.

Hasil dari identifikasi kemudian dipaparkan kembali dalam forum diskusi pelatihan secara tatap muka pada tanggal 12 Mei 2018. Dari hasil identifikasi yang dilakukan peserta tersebut, dapat dinilai bagaimana keterampilan guru PAUD dalam melakukan proses identifikasi. Melalui kegiatan post-test diperoleh kesimpulan bahwa sebanyak $90 \%$ mengetahui jenis-jenis
ABK, sebanyak $55 \quad \%$ mampu mengidentifikasi $\mathrm{ABK}$, dan $50 \%$ mampu mengasesmen ABK.

Dari penjelasan diatas, sebelum pelatihan diketahui bahwa keterampilan guru PAUD dalam mengidentifikasi ABK cukup minim. Hal ini karena keterbatasan pengetahuan guru PAUD mengenai jenis-jenis ABK sebatas pada cacat secara fisik, buta, bisu tuli dan keterbelakangan mental. Sedangkan mereka kurang begitu paham mengenai karakteristik ABK yang mengalami gangguan perilaku. Dengan adanya pelatihan identifikasi dan asesmen ABK, pengetahuan tentang jenisjenis ABK semakin besar, yakni meningkat menjadi $90 \%$. Keterampilan guru dalam mengidentifikasi juga mengalami peningkatan, dari $10 \%$ menjadi $55 \%$ mampu mengidentifikasi ABK, serta adanya peningkatan dalam kegiatan asesmen ABK, dari $10 \%$ menjadi $50 \%$.

Sebagaimana dikemukakan oleh Hapsari (2015), bahwa diperlukan kepekaan dari guru untuk mengenali ciri dan karakter khas dari ABK, sehingga guru dapat melakukan asesmen terhadap potensi positif maupun negatif dari peserta didik. Ditambahkan pula bahwa guru PAUD yang profesional harus mampu melakukan proses identifikasi secara tepat sehingga dapat memberikan langkah penanganan yang sesuai dengan kebutuhan. Demikian juga sebaliknya, jika dalam proses identifikasi keliru, maka berdampak pada langkah penanganan yang keliru pula. Sehingga dikhawatirkan pada jenjang berikutnya, perkembangan dan penanganan anak akan semakin lamban dan sulit.

Minimnya keterampilan guru PAUD dalam mengidentifikasi ABK juga dikarenakan kurangnya pengalaman terdahulu guru tentang ABK dan kurangnya pelatihan yang didapat guru. Sebagaimana dijelaskan oleh Santrock (2006) bahwa pemahaman tentang suatu konsep baru sangat dipengaruhi oleh pengetahuan yang diperoleh sebelumnya. Untuk mengatasi hal ini, tentunya guru perlu aktif untuk mencari pengetahuan mengenai ABK demi memberikan layanan pendidikan yang layak bagi semua. Yang mana sejalan dengan 
tujuan pendidikan untuk semua dan tujuan pendidikan PAUD.

\section{SIMPULAN DAN SARAN}

\section{Simpulan}

Berdasarkan hasil penelitian, dapat disimpulkan bahwa:

1. Antusias peserta pelatihan identifikasi dan asesmen ABK sangat terlihat dari banyaknya pertanyaan dan diskusi peserta dalam mengemukakan permasalahan di kelasnya sehari-hari

2. Keterampilan guru sekolah PAUD Peek A Boo dan PAUD Permata Bunda dalam mengidentifikasi dan asesmen ABK setelah mengikuti pelatihan telah meningkat. Hal ini ditunjukkan dengan deskripsi sebanyak 90\% guru mampu menjelaskan jenisjenis ABK, sebanyak 55\% mampu mengidentifikasi $\mathrm{ABK}$ di kelasnya, dan sebanyak 50\% mampu melakukan kegiatan asesmen ABK.

\section{Saran}

1. Waktu pelaksanaan pemberian materi yang dinilai singkat, dirasa masih kurang bagi guru. Beberapa guru juga menerangkan bahwasannya mereka membutuhkan adanya monitoring tambahan dan berkelanjutan dari ahli terkait pelatihan.

2. Guru perlu aktif dan kreatif dalam mencari pengetahuan mengenai $\mathrm{ABK}$ agar dapat mengidentifikasi secara tepat dan mampu memberikan layanan pendidikan yang maksimal sesuai kebutuhan karakteristik ABK.

\section{REFERENSI}

Adnan, Evita, dkk. 2012. Mengenal Anak Berkebutuhan Khusus. Bahan Ajar Diklat Berjenjang: Diklat Dasar. Direktorat Pembinaan Pendidik Dan Tenaga Kependidikan PAUD NI Direktorat Jenderal PAUD NI Kementerian Pendidikan Dan Kebudayaan

Departemen Pendidikan Nasional. 2003. Undang- Undang Republik Indonesia
Nomor 20 Tahun 2003 tentang Sistem Pendidikan Nasional. Jakarta: Depdiknas

Hapsari, Melati Ismi. (2015). Identifikasi Permasalahan Anak Usia Dini Berkebutuhan Khusus Dan Penanganannya. PSYCHO IDEA, Tahun 13. No.1, Februari 2015

Santrock. (2006). Child Development: third edition. Mc Grew Hill: USA

Suryaningrum, C., Ingarianti, T. M., \& Anwar, Z. (Januari 2016). Pengembangan Model Deteksi Dini Anak Berkebutuhan Khusus (ABK) Pada Tingkat Pendidikan Anak Usia Dini (PAUD) di Kota Malang. Jurnal Ilmiah Psikologi Terapan Vol 04, No 01 Fakultas Psikologi Universitas Muhammadiyah Malang, 62-74.

Kismawiyati, Renalatama. 2018. Identifikasi Anak Berkebutuhan Khusus di Sekolah PAUD Kabupaten Jember. Jurnal Helper, Vol 35 No 1 (2018)

Yaum, L. A., \& Mais, A. (2017). Pelaksanaan Lesson Study Identifikasi dan Asesmen Anak Berkebutuhan Khusus Dalam Setting Pendidikan Inklusif untuk Anak Usia DIni pada Guru PAUD di Kabupaten Jember. Pendidikan dan Humaniora (Jurnal Pendidikan dan Ilmu Pengetahuan Sosial), 78-8 
ABADIMAS ADI BUANA

VOL. 03. NO. 1, JANUARI 2019
e-ISSN : $2622-5719$, P - ISSN : $2622-5700$ 